\title{
Personality Over Time: Methodological Approaches to the Study of Short-Term and Long-Term Development and Change
}

\author{
Jeremy C. Biesanz \\ University of Wisconsin-Madison \\ Stephen G. West \\ Oi-Man Kwok \\ Arizona State University
}

\begin{abstract}
Although theories of personality emphasize the integrative, enduring, and dynamic nature of personality, the current modal research design in personality ignores the dimension of time. We consider a variety of recent methods of longitudinal data analysis to examine both short-term and long-term development and change in personality, including mean-level analyses both across and within individuals across time, variance structures across time, and cycles and dynamic models across time. These different longitudinal analyses can address classic as well as new questions in the study of personality and its development. We discuss the linkages among different longitudinal analyses, measurement issues in temporal data, the spacing of assessments, and the levels of generalization and potential insights afforded by different longitudinal analyses.
\end{abstract}

Jeremy C. Biesanz, Department of Psychology, University of Wisconsin-Madison, Stephen G. West, Department of Psychology, Arizona State University, and Oi-Man Kwok, Department of Psychology, Arizona State University.

We thank Avshalom Caspi, William Graziano, John Nesselroade, Daniel Ozer, and three anonymous reviewers for their valuable comments on an earlier version of this manuscript.

Correspondence should be addressed to Jeremy C. Biesanz, Department of Psychology, University of Wisconsin-Madison, 1202 West Johnson Street, Madison, WI 53706-1696. E-mail: jcbiesanz@wisc.edu.

Journal of Personality 71:6, December 2003.

Blackwell Publishing 2003 
The broad and influential theories of personality by Allport (1937), Lewin (1935), and Murray (1938) all emphasize the integrative, distinctive, enduring, and dynamic nature of personality. To understand these aspects of personality requires considering and examining personality across time. Personality develops and changes both in the long term as a function of maturational processes and in the short term, often as a function of major life events or life transitions. However, the great majority of personality research has remained focused on measures collected at a single point in time. For instance, among the 189 articles published in the 2000 and 2001 volumes of the Journal of Personality and the Journal of Personality and Social Psychology: Personality Processes and Individual Differences, $143(75.7 \%)$ examined personality measures at only one time point. Of note, only 31 articles $(16.4 \%)$ collected three or more assessments. These trends continue despite the development of new methods such as experience sampling, daily dairies, and on-line behavioral sampling that potentially offer rich information about personality functioning in the short run and the increasing number of longer term studies in such areas as clinical, developmental, health, and prevention psychology.

The area of longitudinal data analysis has experienced an explosive growth during the past two decades. Many new techniques have been developed and tried out on longitudinal data sets in a variety of substantive areas. However, many of the newer longitudinal analyses that can potentially contribute to our understanding of the enduring and dynamic nature of personality require, at the very least, multiple assessments (Boker, Xu, Rotondo, \& King, 2002; West \& Hepworth, 1991; Willett, Singer, \& Martin, 1998). Although the great majority of studies of personality over time simply continue to report simple correlational or regression analyses of data collected at two time points, it is clear that there is increasing interest in understanding personality across time. Recent edited volumes and journal special issues have been devoted to considering fundamental questions about the temporal aspects of personality such as the stability and coherence of personality (e.g., Baumeister, 2001; Cervone \& Shoda, 1999; Heatherton \& Weinberger, 1994; West \& Graziano, 1989; the present volume).

The purpose of this article is to present several methods for longitudinal data analysis that may be used or adapted to examine some classic and new questions that arise in the study of personality 
and its development and change over time. Because of space limitations, we limit our presentation to methods that are appropriate for quantitative data. Longitudinal categorical data analysis has also seen great advances (e.g., Collins, Hyatt, \& Graham, 2000; Von Eye \& Clogg, 1996), but such data are much less commonly collected by personality researchers. Some of the examples we report do not utilize core personality variables but rather other variables such as abilities that have been the focus of the initial application of these new techniques.

To provide a framework with which to conceptualize the diverse approaches to personality data, we first review personality's fourdimensional data box (Ozer, 1986). Second, to this point, personality researchers have relied heavily on correlation, multiple regression, and structural equation modeling (see Roberts \& DelVecchio, 2000 for an excellent summary of this work). We introduce alternatives to the traditional analysis of correlational structures that appear to hold promise for thinking about and analyzing the data of personality. These approaches include mean structures across time, both across individuals and within individuals, variance structures over time, and cyclical and dynamic models across time. Third, we discuss contrasts among these methodological approaches in understanding of the nature of personality. Finally, we discuss some measurement and timing issues that can arise in exploring the stability and coherence of personality. Data over time has the potential to greatly increase our ability to answer questions about personality, but it also involves more complex analyses.

\section{Examining Personality: The Four Dimensional Data Box}

How should we think about the data of personality? A framework that provides a useful starting point is Ozer's (1986) simplification of Cattell's (1966a) data box. In this approach, data are potentially organized in terms of four dimensions: persons, situations, responses (measures or constructs), and time. Figure 1 provides an illustration of the full data box with two persons, two situations, four responses, and four time points. Ozer has been one of the few theorists to explicitly examine and argue for these four dimensions (see also West, in press), but many other theorists and researchers have implicitly examined these four dimensions within their own research 
Person 1

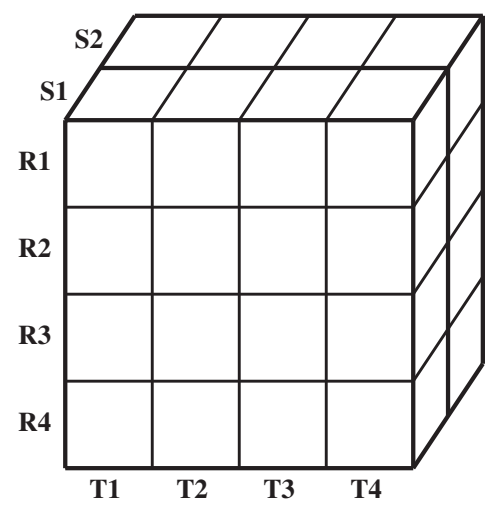

Person 2

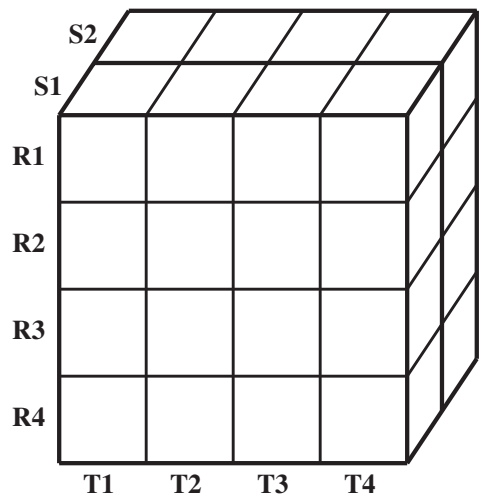

Figure 1

The conceptual data box of personality comprising two persons, two situations (S), four measures or constructs (R), and four time points (T).

(e.g., Bem, 1983; Epstein, 1980; Kelley, 1973; Shoda, Mischel, \& Wright, 1994; Snyder, 1983).

As noted by Ozer (1986), the data box need not always be used in its full form, but rather can be further simplified and adapted to answer the specific questions raised by the researcher. As one illustration, Runyan (1983), drawing on earlier work by Kluckhohn and Murray (1953), noted that personality psychologists may seek any of three different levels of generalization with respect to the persons dimension.

1. Characteristics that are true of all people (general human tendencies). In this case, the persons dimension is of little interest and the data will be aggregated over this dimension. Any variability that is found between persons is ignored or is ascribed to measurement error.

2. Characteristics that are true of some people (individual differences). In this case, the persons dimension is of central interest. Variability between persons is deemed to represent meaningful differences between people.

3. Characteristics that are true of a single individual. In this case, each individual is of interest and the layer of the data box corresponding to that person will be sliced off and analyzed separately in a within-person analysis. 
Consideration of the data box helps us understand the nature of the data required to address these questions of appropriate generalization. The difference between (1) and (2) hinges on the conflicting interpretations of variability between persons as being error variance versus meaningful individual differences. These interpretations can not be adequately addressed in a cross-sectional study as distinguishing between them will require repeated measurements over time. Further, the difference between (2) and (3) concerning the degree of uniqueness of individuals arises in the contrasting perspectives of nomothetic versus idiographic approaches to personality (Allport, 1937; Lamiell, 1997; Magnusson \& Torestäd, 1993; West, 1983; Winter \& Barenbaum, 1999). Once again, the data box helps to clarify that extensive measurements over time and across persons will be necessary to differentiate between these two perspectives on generalization.

Consideration of the data box also encourages us to think about different types of data summaries that might be useful to personality researchers in describing behavior. Traditionally, researchers have focused almost exclusively on correlational structure, correlating the behavior of participants on two measures, in two situations, or at two time points. Such correlations inform us about the rank order consistency of the individuals on the measures, across situations, or over time. These correlations inform us about some important questions facing personality researchers. However, other complementary approaches allow us to address many other important questions that have historically been neglected by personality researchers. Many of these questions are related to the level (mean structure) and variability of personality constructs over time. For example:

1. How does the level of each personality construct (e.g., the Big Five personality traits; moods) change over time as people age? Are there individual differences in these changes?

2. Do people's profile across constructs (e.g., the Big Five) change over time? Are there individual differences in the pattern of these changes?

3. How variable is behavior over time? Are individual differences in the variability in how personality is expressed over time and across situations related to other important outcomes? 
4. Are there meaningful and important rhythms (e.g., weekly mood cycles) in how personality is expressed across time?

In general, the first two questions focus on long-term development, and the last two relate to short-term development. We examine how these and other questions may be addressed, focusing on several recent methodological advances that appear to hold promise for personality researchers. We also examine some of the design, measurement, and conceptual issues that may arise when these approaches are applied to the study of personality over time.

\section{Questions of Mean Structure and Variability of Personality Constructs}

Mean changes across individuals: Individuals across time (Question 1) One aspect of personality that is lost when viewed through the lens of correlational analysis is mean structure. For example, how does the mean level of a personality construct change in the population over the life course? Advances in quantitative methodology (e.g., Mehta \& West, 2000; Meredith \& Tisak, 1990; Raudenbush \& Bryk, 2002; Rogosa \& Willett, 1985; Tisak \& Tisak, 2000; Willett \& Sayer, 1994) now provide flexible frameworks to address many core questions about personality and its growth and development. We consider four approaches to examining questions of mean-level changes across individuals: cross-sectional, longitudinal, accelerated longitudinal, and discontinuous designs.

Cross-sectional designs. One approach to assessing the first question is through a large cross-sectional study taking advantage of the natural variation in age across participants. A particularly good example of this approach is provided by studies by McCrae and Costa (1990) and McCrae et al. (1999) who examined mean levels of the Big Five (Agreeableness, Extroversion, Neuroticism, Conscientiousness, and Openness to Experience) across the adult lifespan using the NEO measure. Using data collected in the United States with the NEO-PI inventory, the results showed that the period from college age (18-21) to middle adulthood (40-49) and older $(50+)$ was associated with declines in Neuroticism, Extraversion, and Openness as well as increases in Agreeableness and Conscientiousness. This cross-sectional analysis of mean levels of personality suggests that these systematic personality changes are a 
general human tendency that occurs over the life course. However, interpreting cross-sectional data as indicative of change requires several assumptions. One strong assumption of this approach is that other major historical events (e.g., the Great Depression, the Vietnam War) did not affect the levels of personality traits differentially as a function of the participant's age. For example, Elder (1998) has documented several differences in the personality of cohorts of children of different ages during the Great Depression. A second strong assumption is that there is not differential mortality that is associated with personality characteristics. For example, Friedman et al. (1995) in a long-term follow up of participants originally measured circa 1930 during their adolescence found that individuals who were low in conscientiousness were likely to die younger than those higher in conscientiousness.

McCrae et al. (1999) were able to replicate their earlier U.S. findings of a general human tendency of age-related change in the Big Five traits of Neuroticism, Extroversion, and Openness ${ }^{1}$ in several different countries (Germany, Italy, Portugal, Croatia, and South Korea). This finding clearly shows the generality of these personality changes across several different nations. It also rules out many forms of artifacts that could result from historical effects on personality development (e.g., the Vietnam War would not be expected to have a significant effect on personality development in children or young adults in the countries studied besides the United States). At the same time, McCrae et al.'s cross-sectional study could not answer questions related to variation and individual differences in change. Does everyone experience systematic declines in their levels of Extraversion, Neuroticism, and Openness over time? Alternatively, does the general pattern of change in the Big Five personality traits characterize all individuals, or is there wide variability among individuals in how their personality changes over time?

Longitudinal designs. Longitudinal studies have classically used a panel design in which a sample of individuals is measured at several different measurement waves. For example, in a short-term longitudinal study of adjustment to college, freshman might be measured every two weeks, whereas in the Berkeley Guidance study, a life-span study of development, adults were measured at ages 18, 
30, 40, and 50 years of age. Traditionally, repeated measures analysis of variance (ANOVA, see e.g., Haan, Millsap, \& Hartka, 1986; Helson \& Wink, 1992) has been used to study the mean level of personality over age. This repeated measures approach offers far greater statistical power than would characterize the analysis of cross-sectional data with the same sample size. However, it does not directly address individual differences in change over time, often one of the primary motivations for longitudinal data collection.

When assessments are gathered on the same individuals over repeated measurement periods, a variety of new models of growth can used to study individual differences in change. Two closely related approaches, hierarchical linear models (Raudenbush \& Bryk, 2002) and latent growth curve models, (Meredith \& Tisak, 1990; Willett \& Sayer, 1994) can be used to answer questions about individual differences in change over time. Mehta and West (2000) show that the two approaches produce identical results under most circumstances and identify a few applications in which one approach may be preferred.

Jones and Meredith (1996) reported analyses of longitudinal data that nicely complement McCrae et al.'s (1999) cross-sectional study. Combining data from the Berkeley Guidance and the Oakland Growth Studies, Jones and Meredith used the latent growth curve approach to model personality change from age 18 to 60 on measures of Self-Confidence (lack of neuroticism), Cognitive Commitment (openness), Dependability (conscientiousness), Outgoingness (extraversion), Warmth (agreeableness), and Assertiveness. Of importance, the results showed mean-level changes across the lifespan on average across individuals for each measure-with the exceptions of assertiveness and warmth. These broad average trends, however, mask significant individual variability in personality change across the lifespan. For instance, the average person became more self-confident (less neurotic) over the course of his or her lifespan, a result that replicates McCrae et al.'s earlier finding. Yet, there were large individual differences between individuals and between two age-cohorts studied in the pattern of growth.

Beyond finding individual variability in data, the new statistical approaches permit examination of several possible explanations of growth and change. These potential explanations are illustrated below with examples of hypotheses that might be tested. 
1. Growth (or decline) may be related to stable background variables. For example, adults whose parents divorced (dichotomous predictor) or who attended a large number of religious services (continuous predictor) during their childhood years may be less likely to show the typical decline in neuroticism as they age.

2. Growth in one series may be related to growth (or decline) in a second series. For example, the rates of change of neuroticism and extroversion may be related. People who show large increases in extroversion during their adult years may show a correspondingly large decrease in neuroticism.

3. Even after the general growth trends in the data of both series are accounted for, one variable may predict changes in another variable (Curran \& Bollen, 2001). Such a model would be particularly appropriate when applied to short-term longitudinal studies in areas such as the relation of daily stress and daily mood following a major negative event (e.g., car accident). Even though stress would be expected to decrease and positive mood would be expected to increase as time since the accident increases, unusually high levels of stress relative to one's expected level might be expected to have a negative relationship with the level of positive mood.

Duncan, Duncan, Strycker, Li, and Alpert (1999) and Singer and Willett (in press) present an introduction to these and other analyses that can potentially account for variability in the series.

We have illustrated the beauty and power of longitudinal designs by providing examples of the kinds of questions that they are particularly adept at answering. However, an important downside of traditional longitudinal studies is waiting for change to occur- 42 years in the case of the data analyzed by Jones and Meredith (1996). A second downside is that, classically, many longitudinal studies have focused on one cohort of individuals, potentially limiting generalization of findings to a single age group. For example, the participants in the Oakland growth study were born in $1920 \pm 1$ year. Fortunately, when data are available as in Jones and Meredith's study, data from different cohorts can be initially tested for cohort effects and then combined in multiple cohort growth models (Mehta \& West, 2000). 
Accelerated longitudinal designs. Following an early design suggestion by Bell (1954), new data analytic approaches now make it possible to make inferences about long-term growth based on data collected in brief longitudinal designs. Accelerated longitudinal designs with as few as even two assessments provide the opportunity to examine variation in individual trajectories of change over the life course.

McArdle, Ferrer-Caja, Hamagami, and Woodcock (2002) provide an excellent recent example of an accelerated longitudinal design examining changes in fluid (e.g., reasoning) and crystallized (e.g., vocabulary) intelligence across the life span. Retest data on intelligence were collected on a large, nationally representative sample of individuals ranging in age from 2 to 95, with retests gathered at different times for various individuals ranging from under a year to as long as 10 years after the first assessment, with an average lag of 2.7 years. Two important conclusions emerged from the analysis. First, different measures of intelligence follow different mean trajectories during the life course. Fluid intelligence reaches a maximum in the late $20 \mathrm{~s}$ and then declines relatively rapidly, whereas crystallized intelligence reaches a point in the late 30 s and stays almost flat with only very minor declines with age. Second, there is substantial variability in the rate of rise, the rate of decline and the maximum level across individuals in both fluid and crystallized intelligence. Note that in order to conduct these analyses, McArdle et al. needed to assume that there were no cohort effects and that individuals follow the same general functional form of change over the life course. ${ }^{2}$ Accelerated longitudinal designs permit only partial examination of these fundamental assumptions; increased overlap among cohort measurements yields more rigorous examinations.

Discontinuous growth designs. Not all growth follows a straight line or a simple nonlinear form. In many children, physical growth suddenly becomes very rapid at some point in early adolescence (the so-called growth spurt). Spatial skills in children show qualitative changes before ages 7-9 and continuous growth thereafter

2. McArdle et al. assumed that all individuals increase to a maximum level and then decrease. However, individuals may vary in the rate of growth, the rate of decline, and the maximum point that is reached. 


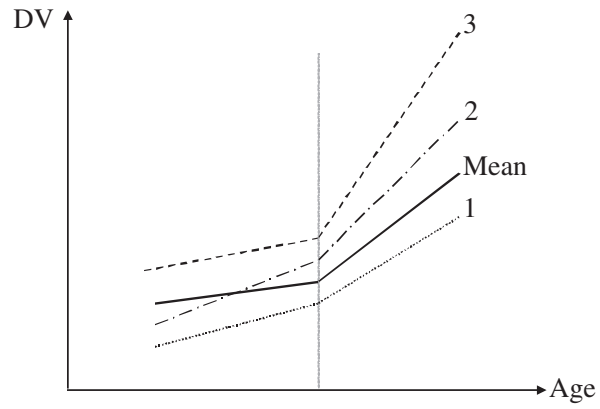

A. Abrupt shift in growth rates but not mean level at a common age.

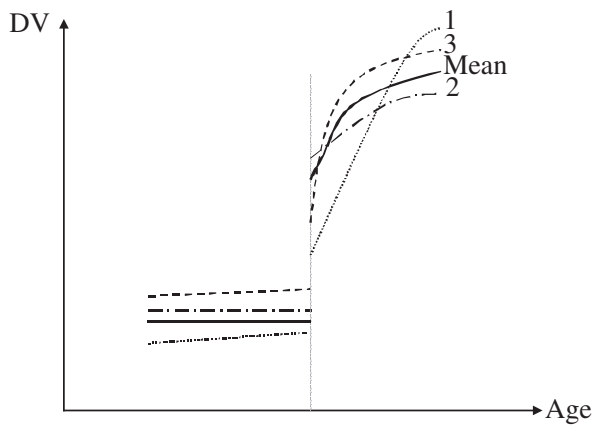

B. Abrupt shift in both growth rates and mean levels at a common age.

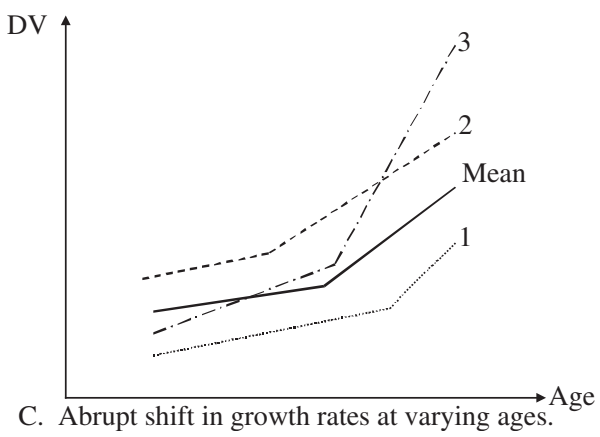

Figure 2

Illustration of possible discontinuities in growth rates and mean levels as a function of age.

(Pellegrino \& Kail, 1982). In the elderly, sudden rapid declines in cognitive functioning just before death are not uncommon. Some theorists like Piaget have models that can be interpreted as 
proposing not only a striking change in the rate of growth but also an abrupt discontinuous shift in level as a child passes from one stage of development into another. These discontinuities in both the rate and level of growth can be represented using piecewise growth models (Cudeck, 1996; Cudeck \& Klebe, 2002). Each segment of the growth process can be represented in the form of a simple linear or nonlinear trajectory with the two segments (a) joined at a point termed a knot if there is only an abrupt shift in the rate of growth or (b) separated at the point of change if there is both an abrupt shift in the level or form of growth or decline. Illustrations of these two types of piecewise growth are illustrated in the first two panels of Figure 2.

An important consideration in the application of these models is whether the point at which the growth process should change is clearly known. For example, the rate of increase in the development of reading skills or peer interaction skills might be hypothesized to shift abruptly at the point of initial entrance to school. As well, personality studies initiated before $9 / 11 / 01$ could examine potential discontinuities on constructs such as relationship measures associated with that historic event. In contrast, the point of onset of the adolescent growth spurt or the point of the hypothesized shift from concrete to formal operations in thinking will vary across children and will not be known in advance. Both cases may be accommodated: The point of transition may be a fixed point, or it may vary across participants and be estimated from the data. The third panel of Figure 2 illustrates this latter case. When the transition point varies across participants, it may potentially be predicted from other characteristics of the participant. Such piecewise models offer an important tool to understand development in which both qualitative and quantitative changes occur.

Mean changes within individuals: Profiles across time (Question 2) A second research tradition in personality has been to focus on coherence - within-person consistency - and to use persons as the central unit of analysis (Caspi \& Bem, 1990). This person-centered research approach focuses on the organization and temporal stability of attributes within single individuals (Magnusson \& Torestäd, 1993). One notable and influential exemplar is Block's (1971) Lives Through Time, which explicitly examined personcentered coherence. Block correlated a set of attributes within a 
person over time (i.e., Q-correlation; see Stephenson, 1952), yielding an index of the consistency/coherence of the set of attributes. Individuals' Q-sorts, determined by judges, showed considerable Q-correlational stability from childhood to young adulthood (see also Ozer \& Gjerde, 1989). Estimates of the temporal stability of a set of attributes within an individual have demonstrated substantial coherence within individuals across diverse contexts (e.g., Biesanz \& West, 2000; Colvin, 1993; Shoda, Mischel, \& Wright, 1994).

Yet correlational studies of coherence ignore all information about level (mean structure). Embedded within the level data are the potential answers to such questions as Do certain constructs within individuals change more than others over time? For example, what is the profile of change of the facets of the Big Five personality traits as people age or experience important life transitions? To address this question, Nasby and Read (1997) sought to determine the potential change in Dodge Morgan's profile on the Jackson PRF and on facets of the Big Five measures of personality as a function of Morgan's solo circumnavigation of the world in a sailboat. We are unaware of empirical or methodological papers comparing trajectories of the profile of personality attributes, but adapting latent growth curve models to this purpose is straightforward.

To more clearly illustrate this approach, consider a set of attributes within an individual such as trait adjectives that are assessed over time. Each assessment provides a snapshot of the organization and patterning of the set of attributes at a single time point within that individual. However, when examined across time, we can ask whether the patterning of the set of attributes is stable or whether there exists meaningful change in the patterning of the assessed attributes across time. Figure 3 presents a hypothetical example of the trajectories among attributes within an individual. Note that such an analysis shifts the focus of the data analysis from the person measured on a specific construct, as in standard latent growth curve models, to the construct measured within a single individual.

To illustrate, we present an analysis of data from a single 21-yearold female undergraduate who self-reported her level on 59 trait adjectives selected from Goldberg (1992) (for details of the data collection procedures, see Biesanz \& West, 2000; Biesanz, West, \& Graziano, 1998). The first assessment was in the middle of the fall 


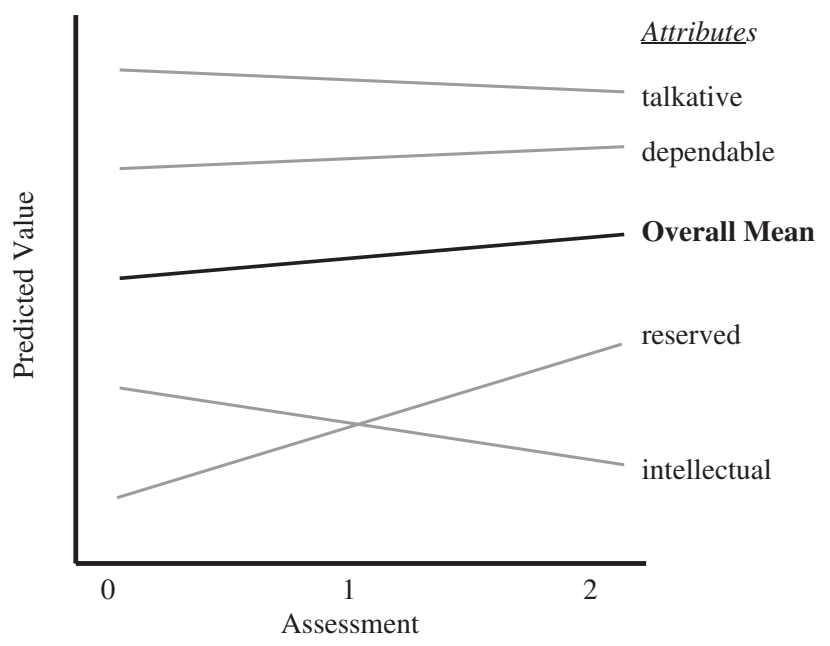

Figure 3

Illustration of modeling change in mean levels of attributes (trait adjectives) within a single individual.

semester, with the second occurring 7 days later and the third 21 days after the initial assessment. We focus here on the 59 personality trait descriptors representing Extraversion, Neuroticism, and Openness, which would have been expected to show overall decline over the lifespan. If we had measured the trait adjectives over a much longer time period, from McCrae et al. (1999) we would expect the average person to manifest a decline across these three broad constructs. However, over such a short time interval, substantial mean level change on these constructs is clearly not expected in the absence of a major life event.

We estimated a growth model that allowed for possible linear change over the three assessments using EQS (v. 5.80; Bentler, 1995). This model resulted in an adequate fit to the data, $\chi^{2}$ (3, $n=59)=1.97, n s, \quad \mathrm{CFI}=1.00, \quad \mathrm{SRMSR}=.031, \quad \mathrm{RMSEA}=0.00$. Note that (1) the sample size is the number of attributes assessed within the individual (here, 59), (2) trait adjectives were reverse coded where applicable so that higher responses indicated more Extraversion, Emotional Stability (lack of Neuroticism), and Openness, and (3) time was coded as the number of days after the initial assessment preserving the unbalanced assessment sequence. After estimating and removing the effect of measurement error at 
each assessment - constrained to be equal across the three assessments - we found that the mean level $\left(\hat{\mu}_{\text {initial }}\right)$ was 4.41 on a 0 (extremely inaccurate) to 8 (extremely accurate) scale across the 59 trait adjectives at the initial assessment and that there was significant variability across the level of attributes at the initial assessment, $\hat{\sigma}_{\text {initial }}^{2}=1.83, p<.001$. This estimate reflects the variance across the trait adjectives at the first assessment after removing assessmentspecific effects. This variance estimate reflects both variance among trait adjectives - which are all coded in the more socially desirable direction - and mean-level differences across the three broad traits of Extraversion, Emotional Stability, and Openness for this particular individual.

Of more importance, there was no significant linear mean change across assessments, $\hat{\mu}_{\text {slope }}=0.005, n s$, and no significant variability in the slopes of the 59 trait adjectives over time, $\hat{\sigma}_{\text {slope }}^{2}=0.0002, n s$. The lack of significant variance in the slopes of the trait adjectives indicates that there was no differential change in the profile of the ratings over time on the set of trait adjectives. Similar findings were also obtained with data from the six other individuals from the sample who were studied. These nonsignificant results presumably stemmed from the very short time intervals between assessment periods so that little reliable change in profiles would be expected to occur.

The interpretation of profile analyses depends very strongly on the attributes that are selected and measured. If the selected attributes are expected to be changing in the same downward direction, then the data for the average person should show a negative mean downward trend over a sufficiently long period of time. This was the rationale for our selection of trait adjectives in the present example. In the absence of such specific selection of attributes, the overall mean trend would in general not be predictable. More complex nonlinear forms of change over time could also potentially be examined if more than three measurement waves are included.

Of particular importance in such analyses are measures of variance across attributes in the trend components (slopes). High coherence implies that the variance should be low, whereas low coherence implies that variance should be high because each attribute is changing at a different rate over time. Given that variance of the trend components becomes the key indicator of coherence, researchers are encouraged to sample personality 
attributes broadly within their domain of interest. For example, using a random sample or stratified random sample of personality trait adjectives may produce a better understanding of changes in general coherence over time than the use of Goldberg's (1992) trait adjectives, each of which is focused primarily on a single dimension of the Big Five.

To this point, we have emphasized that these analyses should be conducted on a single individual. However, the same analysis can be conducted separately on each individual in the sample and the resulting mean and variance of the rate of change of the attributes computed. The results for each person in the sample can be compared and summarized through meta-analytic procedures (see Busk \& Serlin, 1992 and West \& Hepworth, 1991 for meta-analytic approaches to single cases; see Adams, Gurevitch, \& Rosenberg, 1997 for meta-analysis of variances). Additional questions can also be raised. For example, if variances of the rate of change differ across individuals, are there stable individual differences (e.g., gender) that predict these differences in the variance of the rate of change?

Such analyses offer the promise of providing an important new perspective on coherence, but they come at a cost. They place a heavy burden on our current measures of personality attributes. An important underlying assumption of these analyses is that each attribute is measured on the same interval level scale of measurement. Measures of physical growth (e.g., length of fingers, toes, arms, trunk, etc.) clearly meet this assumption so that studies of the coherence of physical growth could currently be conducted. However, our typical measures of trait adjectives, moods, and other personality measures have not been shown to meet this assumption. Careful measurement work (e.g., perhaps using IRT approaches) will be necessary for the optimal application of these procedures.

\section{Variance structures across time (Question 3)}

Correlational analysis may overlook another important component of personality data collected over time. Conceptually, the mean structure of the data can be considered to be independent of the variance structure. ${ }^{3}$ If repeated measures are collected over time on

3. Technically, this is true in many statistical distributions, but not all. The independence of means and variances characterizes the normal distribution, which underlies the statistical models presented here. In some other statistical 
the same set of individuals, each person may differ in the amount of variability he or she displays on personality constructs such as a trait, self-concept, or mood. Returning to the data box, this intraindividual variability may reflect in part the aggregation of data over situations. For example, individuals high in extraversion may enter a much wider variety of social situations than their introverted peers (Diener, Larsen, \& Emmons, 1984). In this case, variability in personality attributes over time can be considered to reflect, in part, variability in the situational choices that each person makes. However, we can also slice off a single situation from the data box and study variability over time within the single situation. Even when the role of the situation is controlled, different individuals may display different levels of variability over time. Fiske and Rice (1955) provide an extensive review of support for individual differences in stable intraindividual variability overtime across many different domains of behavior including physical motor skills (Allport \& Vernon, 1933), heart rate (Herrington, 1942), and spelling nonsense syllables (Thorndike, 1931). Many early personality theorists and researchers hypothesized that such variability represents important individual differences (Cattell, 1966b; Dodge, 1924; Murray, 1938).

More recently, researchers have moved from simply documenting these stable individual differences in intraindividual variability and have begun to explore its structure and predictive validity. To cite two examples, Eizenman, Nesselroade, Featherman, and Rowe (1997) collected daily measures of locus of control in an elderly population. The amount of within-person variability predicted mortality five years later. Butler, Hokanson, and Flynn (1994) measured self-esteem on a daily basis and computed measures of the mean and variability of self-esteem. They found that the variability was far better than the mean level in predicting proneness to depression. Other examples of using intraindividual variability of measures to predict important outcomes can be found in studies by Kernis, Grannemann, and Barclay $(1989,1992)$ for excuse making and tendency to experience anger and hostility, Chen, Aggen, Nesselroade, and Baltes (2001) for memory, and Lang, Nesselroade and Featherman (1997) for perceptions of social self-efficacy and 
relationship availability. Given the relative paucity of research to date, our understanding of intraindividual variability remains much less complete than that of correlational structures. For example, does variability on one construct relate to variability on a second construct? More generally, are there structures across individuals in terms of intraindividual variability over different domains? How do these structures compare to the more familiar structures based on correlational data such as the Big Five? As the research to date indicates, intraindividual variability in personality may be of particular importance to our understanding of the self.

Two difficulties have hindered progress towards answering questions about intraindividual variability over time. First, gathering estimates of intraindividual variability requires more intensive and expensive data collection procedures. Second, estimates of variability are less reliable than mean estimates, meaning that more measurements will need to be collected to get precise estimates of intraindividual variability. In large samples, the standard error of the mean is $\sigma / \sqrt{n}$, whereas the standard error of the variance is approximately $1.4 \sigma^{2} / \sqrt{n}$ (Kendall \& Stewart, 1977) where $n$ is the number of assessments of a person. The recent development of beeper, diary, and other methods of event sampling for measuring personality attributes on a within-day, daily, or weekly basis has greatly increased the availability of such data and has helped overcome these difficulties. Examination of within-subject variability can now serve as a useful complement to examination of correlational and mean structures.

\section{Cycles and dynamic models across time (Question 4)}

Although raw variability in behavior across time within a given domain appears to be a stable individual difference and is linked to important outcomes, it can also be fruitful to attempt to model and understand the origins and patterning of regular changes across time. Human activity tends to follow daily, weekly, monthly, and yearly patterns (cycles), and these cycles may be associated with important personality-related processes. To cite two examples, Armeli, Carney, Tennen, Affleck, and O'Neil (2000) found in a community study that daily stress tended to be highest in the middle of the work week, whereas alcohol consumption tended to be highest on Friday and Saturdays. Anderson and Revelle (1994) found individual differences in within-day variation in arousal cycles and 
that such within-day variation in arousal was related to performance on cognitive tasks. In terms of the data box, the first finding may reflect entry into situations (bars, parties) associated with alcohol consumption on weekends. In contrast, the cycle of daily activation presumably reflects internal bodily rhythms, and that would be expected to occur even if the individual remained in the same situation.

In one of the most extensive studies of daily cycles, Brown and Moskowitz (1998) examined daily cycles in interpersonal behavior. Participants completed a form measuring interpersonal agency and communion (Wiggins, 1991) over the course of 20 days after every social interaction that lasted more than 5 minutes. Although individuals manifested substantial relative consistency in their behavior on both interpersonal agency and communion, there were predictable patterns in variation of the behavioral reports. Interpersonal agentic and communal behaviors fit a weekly cyclical pattern of variation. More interestingly, the amount of within-day interpersonal behavioral variability was predicted by the trait of extraversion. Extraverted individuals also engaged in a higher mean level of social activities than introverted individuals. In turn, this led to more within-day variability in agentic and communal behaviors. Thus, Brown and Moskowitz (1998) found that the individualdifference variable of extraversion is related not just to stable differences among individuals in their mean levels of behavior, but also to their variability in behavior over time (see also Biesanz \& West, 2000).

Methods of detecting regular cycles in temporal data are described by Larsen (1990) and West and Hepworth (1991). Of particular value are spectral analyses that determine the period(s) at which consistent fluctuations in the series tend to occur. Period is defined as $1 /$ time. For example, if data were collected on a daily basis and there were a weekly cycle, a very strong relationship between the fluctuations in the series would be found at a period of $(1 / 7$ days $)=.142$ in the results. Such regular relationships are easily seen in spectral density plots in the form of a high spike in the plot at the point corresponding to the cycle (see West \& Hepworth, 1991, p. 622, Figure 2, for an example). This approach can be extended to examine the relationships between the cycles in two series, a technique known as cross spectral analysis. For example, Armeli et al. (2000) find a negative relationship between the weekly stress cycle (highest on Wednesday, lowest on 
Saturday) and the weekly drinking cycle (highest on Saturday, lowest on Monday). Given that a very large number of observations over time are collected, as when on-line recording techniques are used (e.g., speech, movement), irregular cyclic relationships that come and go between two series can also be detected through algorithms that divide the series into segments and search for local relationships (Boker, Xu, Rotondo, \& King, 2002). For example, in dyadic conversations, there may be segments in which the speech of one participant is highly related to the nonverbal cues of the second participant and periods in which speech and nonverbal cues are not closely coordinated.

Given appreciable differences between individuals in their regular cycles (e.g., there are large individual differences in daily activity cycles with some people being more active in the morning and others in the evening), cycles should be modeled separately for each individual participant. Typically, at least 50 (preferably 100) regularly spaced observations are needed for such analyses. Such cycles can be modeled by using dummy variables or combinations of sine and cosine functions to represent the cycle (see West \& Hepworth, 1991). In cases in which the same cycle can be assumed to characterize each of the participants in the sample (e.g., a weekly stress cycle that is common to all participants), multilevel analysis can be used to model the cycle with fewer observations per participant, but more participants. As we will consider in more depth in a later section, the multilevel analysis "borrows strength" from the replication of the same cycle across participants. Nonetheless, a minimum of two times the length of the cycle (e.g., 14 observations for a weekly cycle) are needed to be able to detect the cycle.

One of the more exciting recent methodological developments is to model change over time and intraindividual variability simultaneously. A promising start has been provided in the form of a simple dynamic model patterned after a damped linear oscillator. Boker and Nesselroade (Boker, 2001; Boker, 2002; Boker \& Nesselroade, 2002) argue eloquently, using simulated data, that it may be possible to capture and model intraindividual variability with as few as three assessments per individual. Once again, a trade-off must be made between being able to model each person separately, which requires collecting a large number of observations on each individual, versus assuming a common process that characterizes all individuals, which greatly reduces the number of observations per person. 
Such models offer the promise of being able to represent dynamic theoretical processes such as self-regulation. Although the practical empirical limitations remain to be determined, the clear promise of such techniques warrants substantial consideration and empirical investigation.

\section{Measurement, Design, and Conceptual Issues in Examining Time}

We now turn to a number of practical and conceptual issues that may arise in examining questions of long- and short-term development and change. First, we consider measurement issues associated with examining personality across time. We then turn to practical issues associated with gathering data across time. Finally, we explore several conceptual linkages among different methods for examining questions of development and change.

\section{Some measurement issues}

Moving beyond correlational analyses to the examination of mean and variance structures brings to the forefront a number of different measurement issues. What types of data are required to examine mean and variance structures? How do we provide individual assessments from latent variable models? We consider these questions below and discuss several specific measurement issues that may arise.

The scale of measurement. The use of self-reports and reports of knowledgeable informants dominate measurement in most areas of personality research. These choices have been supported in much of the research to date: Self- and other-reports on standard rating scales often show at least moderate convergence if some aggregation has taken place, and these reports often predict important real-world criteria (Funder \& West, 1993). Similarly, informant reports show substantial convergence with systematic behavioral observation, again if aggregation has taken place (Moskowitz \& Schwartz, 1982; Moskowitz, 1986). Such measurement choices are well justified when the focus of the research question is on correlational structure. As detailed by Roberts and DelVecchio (2000), a variety of important questions about the rank order stability of individuals across time have been answered using these measures. However, when we turn 
to questions about mean and variance structures over time, such measurement techniques will not always be adequate.

Consider the trait "physically active." If a pedometer or other measure of physical movement is attached to each participant and physical activity is measured over a few days, a high correlation will be obtained between the behavioral measure and self- or informant reports on a standard rating scale of physical activity (e.g., 0 to 10 scale). Suppose these same measurements are taken on a group of participants when they are 30 and again when they are 60 years of age. At each age, the correlations between the behavioral, self-, and other-reports will be high. In addition, the stability, as represented by the correlation between any of the measures of physical activity taken at age 30 and any of the measures of physical activity taken at age 60 , will be at least moderate in magnitude. Such correlations are often buttressed by explicit or implicit instructions to raters to rate the target person in comparison to others of his or her gender and age. However, the level of each participant on the physical measure of activity is likely to be substantially lower at age 60 than age 30 . Current measurement using self- and informant reports preserves rank order, but not level stability. When we wish to reach conclusions about changes in mean level or variance over time, we need to be confident that change is in the personality of the participant, not in our assessment instrument. Estimating growth and decline trajectories requires at least an interval level of measurement (Stevens, 1951).

Fiske (1972) in Measuring the Concepts of Personality noted this problem and forcefully advocated for the use of behavioral measures in personality. Unfortunately, the practical limitations of collecting sufficient behavioral data to provide adequately reliable measures of most personality constructs are too severe. More can be done with the use of careful observer instructions and the use of carefully anchored points on the rating scale to improve measurement. It may also be possible to collect both rating and behavioral measures in a random subset of the sample and to link the two measures, preserving the interval level of measurement. Finally, modern measurement theory such as item response theory can be used to construct interval level measurement scales that can be equated across age (see Embretson \& Reise, 2000). Khoo and West (in press) review a number of approaches that can help preserve interval level measurement and avoid the interpretational problems 
that result from attempting to measure growth with a "rubber ruler."

Latent variables-Providing estimates for individuals. The power of recent advances in quantitative methodology often derives from the ability to separate the measurement of the construct of interest from what is considered measurement error within the overall model. The cost is that the construct of interest must be modeled as a latent variable (see Bollen, 2002); we do not have direct measures of the latent construct (true scores) on such measures as growth, change, variability, or mean levels for specific individuals. However, in some applications, it may be desirable to estimate how much each specific individual changes on a given construct over a period of time.

As we have seen previously in our discussion of modeling cycles, researchers must once again make a choice between using only data from a single individual and combining data from the entire group and the individual. One method to compute factor scores is to use Bartlett's (1937) estimate, which considers each individual separately and ignores the information available in the mean and variance of latent scores across individuals. Consequently, Bartlett's estimates of the value of factor scores are unbiased for each individual, but the variability of these factor score estimates across individuals is greater than the true latent variability. A second class of approaches (Lindley \& Smith, 1972; Tucker, 1971), known as empirical Bayes estimates (or factor regression estimates), combines information from the model for the entire sample with information from the individual subject. Such empirical Bayes factor score estimates are attenuated ("shrunken") toward the mean of the sample, and estimates have less variability than the true latent variability. If the assumptions underlying both the overall model and for borrowing strength (see Tukey, 1986/1961, p. 277) from other individuals are met, however, predictive accuracy can be enhanced through the use of empirical Bayes methods. A third class of estimates (McDonald, 1981) attenuates the Bartlett's estimates just enough to produce estimates that are as variable as the latent construct. Note that these latter two methods, which attenuate individual scores, may not be appropriate for specific individuals who are the a priori focus of attention (i.e., Runyan's (1983) third level of generalization). Biesanz, Curran, and Bollen (2002) present a detailed discussion of factor score estimates and recommendations for when 
each approach should be used, focusing on the context of latent growth curve models.

Issues associated with time

Including time as a feature within a study raises a number of conceptual and practical issues for the study of personality development. We consider several of these issues in turn below.

The number of assessments. Our survey of the 2000-2001 volumes of the Journal of Personality and Social Psychology and the Journal of Personality showed that when data are collected over time, the modal number of assessments collected across time is still two. This is insufficient to examine many of the questions raised within the present manuscript. For example, estimating the variability in simple linear change across individuals generally requires at least 3 assessments. Four or more assessments are required to model the form of change over time and to examine predictors of rates of change. A bare minimum of 50, and likely substantially more, observations are needed to model cycles in behavior and relationships between cycles in single individuals. These requirements can be reduced by assuming that a common growth or cyclical process characterizes all individuals in the sample, an assumption that may or may not be reasonable depending on the research context.

The spacing of assessments. Our focus on the number of assessments is immaterial if they are not collected at the right times. There are two aspects to this issue. First, in approaches such as latent growth curve analysis, the use of unequally spaced intervals precludes answering some, but not all, questions of possible interest. From an analytic standpoint, traditional designs, in which measurement waves are equally spaced and data are complete, permit testing of the widest variety of statistical models, typically with the greatest statistical power. On the other hand, if measurement waves are not equally spaced, it is more difficult to interpret analyses in which a measurement in one series predicts a measurement in a second series at a later point in time (e.g., a lagged relationship; see Curran \& Bollen, 2001). Yet designs with multiple cohorts that overlap substantially (e.g., cohort 1 is measured at ages 20,30, 40, and 50 and cohort 2 is measured at ages $30,40,50$, and 60 so that three measurement ages of 30,40 , and 
50 overlap) permit strong tests of cohort effects and historicalnormative influences. Nonetheless, new analytic models are versatile, and many important questions can be answered even with data that are not well structured relative to the traditional guidelines. For example, measures may be collected at different intervals and at different ages on each participant $(18,40,45,50$ for participant 1 ; 20, 30, 40, 50 for participant 2). Data may be missing from one or more measurement periods ${ }^{4}$ (e.g., 20, 30, M, 50 for participant 1; 20, M, M, 50 for participant 2, where $\mathrm{M}$ indicates data are missing).

Second, the phenomenon of interest must have sufficient time to take place during the full observational period. The profile example presented earlier illustrates this problem since all three assessments were collected within a one month time period. Clearly, not enough time had elapsed to capture the expected slow decline in the level of personality traits. Long intervals between assessments afford the greatest opportunity to detect all monotonic forms of long-term growth and decline. On the other hand, when assessments are spaced substantially apart in time, a real danger exists of missing important information about within-person variability, cycles, and other nonmonotonic patterns of change. Consequently, Nesselroade (2000) has proposed combining long-term assessments with short "bursts" of assessments that occur more frequently. The strong benefits of such data collection designs include the ability to combine the optimal information about long-term growth with information about within-individual variability and cycles and answer new questions. For example, are individuals who are more variable over short periods of time more likely to change meaningfully over longer periods of time? Does an increase in within-person variability predict a qualitative change in the rate of growth?

4. Technically, data are assumed to be missing at random (MAR). MAR means that attrition may be related to the subject's level on measured variables, but not to the participant's level on the missing outcome variable. For example, in a sample of alcohol abusers, if participants were more likely to miss measurement of the amount of alcohol consumption following a heavy binge drinking period, this would violate MAR, and missing data techniques could yield biased results. Schafer and Graham (2002) present an extensive introduction to missing data, and Little and Schenker (1995) discuss special problems of missing data in longitudinal studies. 
The metric of time. Once assessments are gathered, how should time be scaled? Typically, age or some other simple metric (e.g., grade level) is used by default in developmental studies, but there may be other more fruitful choices for the metric of time, depending on the specific research question. The two issues are determining (1) the origin of time and (2) the units of time. Considering first the origin, age in years sets the origin at birth. However, some phenomena cannot be measured until later in life. For example, in observational studies of the development of vocabulary, the first year of life generally will not yield utterances codable as words by outside observers for any child in the sample. From the perspective of growth modeling, it is far more sensible to set the origin at 12 months and to model the nonlinear increase in children's vocabulary from that point in time (i.e., time $=$ age in months -12). Alternatively, if the focus of the study is on a major life transition (e.g., recovery from a serious accident; children's adjustment following the divorce of their parents), then centering each individual's origin to coincide with the transition may be a logical choice. For certain statistical models such as latent growth curve models, placing each individual on the exact same metric with the same age-based or event-based origin may be necessary to provide unbiased estimates of some effects of interest (Mehta \& West, 2000).

The second and more controversial issue is to use alternatives to the actual spacing in time. For example, von Eye, Kreppner, Spiel, and Weßels (1995) have suggested using the subjective experience of elapsed time in some research contexts, and Brim and Ryff (1980) have proposed considering time as an ordinal sequence of normative life events. Such suggestions may offer conceptual advantages if they more adequately represent the "true" metric of time for each individual participant. For example, the growth in the new metric may take a much simpler form (e.g., linear) than in the original metric of time. Unfortunately, these alternative metrics may also introduce complications in interpreting many of the statistical models. While physicists have provided us with a scale of time that has clear equal interval properties, there is no guarantee that the subjective measure of time will achieve these same measurement properties.

Natural confounding of time and situation. One of the challenges of examining time as a feature of personality development is that time 
is naturally confounded with situations. This confounding occurs at a number of different levels. As we observed with the Berkeley longitudinal studies, observing a single cohort over a long period of time naturally confounds age with cultural and historical trends. Age is also naturally confounded with important normative developmental tasks such as going to school, going to work, marriage, and raising one's own children. At the more molecular level of daily and weekly cycles, most individuals have a structure or routine such as moving from family to work roles that occurs regularly both within days and within weeks. In terms of the data box, such confounding can be viewed as having incomplete data. We do not normally observe 10 -year-olds in an office setting nor do we often observe 50-year-olds in a school setting. Instead, as individuals progress through their lives, some situations may be continually present and then come and go (e.g., visits to one's parents home), whereas other situations may fall out of people's lives, being replaced by new situations (e.g., school to work).

Fully disentangling time from changes in situations is neither possible nor desirable. Attempting to do so runs the risk of discarding the core features of people's lives. What then are the alternatives? The use of multiple cohorts helps minimize the impact of historical and cultural trends in addition to providing insight into the specific impact of particular events. Examining how variations in normative timing impacts development can potentially shed light into the role of normative life transitions (Caspi, Bem, \& Elder, 1989). Time series analyses and other assessment-intensive statistical models can incorporate data on systematic changes in social roles. Beyond the role of normative situations is the interplay that comes from individuals choosing situations that, in turn, may powerfully affect the individual's development. Only some children choose to affiliate with deviant peers, but continued affiliation with deviant peers then greatly increases the risk of subsequent delinquent behaviors. From the standpoint of the data box, this is a problem of understanding the determinants of situational selection, an area in which far too little is known.

\section{Linkages among methods}

To this point, we have examined different analyses for exploring personality development in isolation. We now consider the potential linkages among several combinations of these models and how one 
analysis may shed light on or present difficulties in the interpretation of another.

Mean-level and profile analyses across time. Individual differences in mean level changes strongly imply that personality reorganizes across time. Unless the association among rates of change across constructs is perfect, between-persons variance in growth rates provides indirect evidence that the relative patterning of constructs within individuals is changing. However, the exact nature of potential reorganization will be unclear from mean-level analyses. Considering changes in a particular construct over time across individuals in conjunction with changes in constructs within an individual over time is required to fully understand how personality changes over time both nomothetically and idiographically. Although models that estimate both levels of change simultaneously are not currently practical, it is possible to estimate each type of model of change and compare their results, thus providing a greater understanding of how personality is changing over time.

Mean-level and intraindividual variability analyses across time. Both conceptually and mathematically, mean and variance structures can usefully be considered to be independent (see footnote 3 ). Increases in variance may provide a signal of the onset of a dynamic process that only later becomes evident in the mean structure. As mentioned earlier, Butler et al. (1994) found that high variability in self-esteem ratings was associated with proneness to later depression. Sharp improvements in skilled individual performance are often predicted by a period of highly variable performance. Speculatively, increases in intraindividual variance may be leading indicators of qualitative changes in the level or slope of growth or decline.

Strong between-person differences in intraindividual variability (e.g., some individuals are much more variable on a given construct over time than others) may have implications for person-centered analyses. When constructs such as life events and mood are repeatedly assessed as in a diary study, it is possible to model the relationship between mood and self-esteem separately within individuals and then predict that relationship in hierarchical linear and growth models (e.g., Kenny, Kashy, \& Bolger, 1998; Reis \& 
Gable, 2000). We will obtain more precise estimates of the relationship between the two constructs for individuals who are highly temporally variable compared to individuals who are less temporally variable on the independent variable (IV) in the analysis. Consequently, many statistical models that use empirical Bayes estimation will give greater weight to those individuals who are more temporally variable on the IV. This feature may present interpretational problems if intraindividual variability is related to the relationship between the two constructs.

\section{DISCUSSION: Methods and Models}

In this article we have considered a number of new methods for the study of personality in both the short and long term. While traditional correlational methods have served the field by providing answers to some key questions, other important questions have gone unaddressed. The examination of mean structures, variance structures, and cyclic patterns provides a nice complement to the information that can be gleaned from the analysis of correlational structures. Developmental theorists like Cairns (2000), Magnusson (1998; 2000) and Nesselroade and McArdle (1997) have repeatedly called for a stronger convergence between theoretical models and the methods that are chosen to address them. It is clear from our review of recent publications in personality psychology that the lack of breadth of methodologies in current use in personality must by necessity limit the variety of theoretical models of development and change that are under consideration. Given the recent development of a variety of quantitative methodologies for examining personality across time, methodological resources are now currently available to examine more nuanced questions concerning the functioning of individuals over time.

Any one analysis considers only a few aspects of the data box and thus presents only an abbreviated and condensed aspect of personality. Each analytic perspective on the data box provides us with a new piece of the overall puzzle of personality (Funder, 2001). The challenge of the puzzle is for theorists and researchers to recognize that each piece we obtain reflects only a partial view of reality. The pieces will not nicely "fit" together and combine additively with other pieces. No one methodology or analysis can 
adequately represent the full range of models of personality across time.

To illustrate, consider the four questions we posed in the introduction with regard to examining personality over time. It may be possible for a single study to collect sufficient data to examine individual differences in mean-level changes on constructs over time, profile changes across time, individual differences in the variability across time, and meaningful and important rhythms in how personality is expressed over time. As well, sufficient data collection would permit determining if changes are related across constructs (across individuals). Returning to the generalizations that, as Runyan (1983) noted, personality psychologists seek to make, some of these analyses across time provide information about characteristics that are true for each individual. Other analyses can provide information that is true of some people and inform us of potentially meaningful individual differences. And some analyses can provide us with information that characterizes single persons. Deciding when each of these approaches will be most valuable, and integrating the results of these different analyses into a coherent picture of personality to compare against theoretical models remains the challenge.

\section{REFERENCES}

Adams, D. C., Gurevitch, J., \& Rosenberg, M. S. (1997). Resampling tests for meta-analysis of ecological data. Ecology, 78, 1277-1283.

Allport, G. W. (1937). Personality: A psychological interpretation. New York: Holt.

Allport, G. W., \& Vernon, P. E. (1933). Studies in expressive movement. New York: Macmillan.

Anderson, K. J., \& Revelle, W. (1994). Impulsivity and time of day: Is rate of change in arousal a function of impulsivity? Journal of Personality and Social Psychology, 67, 334-344.

Armeli, S., Carney, M. A., Tennen, H., Affleck, G., \& O’Neil, T. (2000). Stress and alcohol use: A daily process examination of the stressorvulnerability model. Journal of Personality and Social Psychology, 78, 979-994.

Bartlett, M. S. (1937). The statistical conception of mental factors. British Journal of Psychology, 28, 97-104.

Baumeister, R. F. (Ed.) (2001). Target article: \Personality development across the life course: The argument for change and continuity. Psychological Inquiry, 12 (2). 
Bell, R. Q. (1954). An experimental test of the accelerated longitudinal approach. Child Development, 25, 281-286.

Bem, D. J. (1983). Toward a response style theory of persons in situations. In M. M. Page (Ed.), Nebraska symposium on motivation 1982: Personalitycurrent theory and research (pp. 201-231). Lincoln, NE: University of Nebraska Press.

Bentler, P. M. (1995). EQS structural equations program manual. Encino, CA: Multivariate Software.

Biesanz, J. C., Curran, P. J., \& Bollen, K. A. (2002). Estimating individual trajectories in latent growth curve models. Unpublished manuscript.

Biesanz, J. C., \& West, S. G. (2000). Personality coherence: Moderating self-other profile agreement and profile consensus. Journal of Personality and Social Psychology, 79, 425-437.

Biesanz, J. C., West, S. G., \& Graziano, W. G. (1998). Moderators of self-other agreement: Reconsidering temporal stability in personality. Journal of Personality and Social Psychology, 75, 467-477.

Block, J. (1971). Lives through time. Berkeley, CA: Bancroft.

Boker, S. M. (2001). Differential structural modeling of intraindividual variability. In L. M. Collins \& A. G. Sayer (Eds.), New methods for the analysis of change (pp. 3-28). Washington, DC: American Psychological Association.

Boker, S. M. (2002). Consequences of continuity: The hunt for intrinsic properties within parameters of dynamics in psychological processes. Multivariate Behavioral Research, 37, 405-422.

Boker, S. M., \& Nesselroade, J. R. (2002). A method for modeling the intrinsic dynamics of intraindividual variability: Recovering the parameters of simulated oscillators in multi-wave panel data. Multivariate Behavioral Research, 37, 127-160.

Boker, S. M., Xu, M., Rotondo, J. L., \& King, K. (2002). Windowed cross-correlation and peak picking for the analysis of variability in the association between behavioral time series. Psychological Methods, 7 (3), $338-355$.

Bollen, K. A. (2002). Latent variables in psychology and the social sciences. Annual Review of Psychology, 53, 605-634.

Brim, O. G. Jr., \& Ryff, C. D. (1980). On the properties of life events. In P. B. Baltes \& O. G. Brim Jr. (Eds.), Life-Span development and behavior, (Vol. 3, pp. 367-388). New York: Academic Press.

Brown, K. W., \& Moskowitz, D. S. (1998). Dynamic stability of behavior: The rhythms of our interpersonal lives. Journal of Personality, 66, 105-134.

Busk, P. L., \& Serlin, R. C. (1992). Meta-analysis for single-case research. In T. R. Kratochwill \& J. R. Levin (Eds.), Single-case research design and analysis: New directions for psychology and education (pp. 187-212). Hillsdale, NJ: Lawrence Erlbaum Associates.

Butler, A. C., Hokanson, J. E., \& Flynn, H. A. (1994). A comparison of selfesteem lability and low trait self-esteem as vulnerability factors for depression. Journal of Personality and Social Psychology, 66, 166-177. 
Cairns, R. B. (2000). Developmental science: Three audacious implications. In L. R. Bergman, R. B. Cairns, L.-G. Nilsson, \& L. Nyystedt (Eds.), Developmental science and the holistic approach (pp. 49-62). Mahwah, NJ: Lawrence Erlbaum Associates.

Caspi, A., \& Bem, D. J. (1990). Personality continuity and change across the life course. In L. A. Pervin (Ed.), Handbook of personality: Theory and research (pp. 549-575). New York: Guilford Press.

Caspi, A., Bem, D. J., \& Elder, G. H. Jr. (1989). Continuities and consequences of interactional styles across the life course. Journal of Personality, 57, 375-406.

Cattell, R. B. (1966a). The data box: Its ordering of total resources in terms of possible relational systems. In R. B. Cattell (Ed.), Handbook of multivariate experimental psychology (pp. 67-128). Chicago: Rand McNally.

Cattell, R. B. (1966b). Patterns of change: Measurement in relation to statedimension, trait change, lability, and process concepts. In R. B. Cattell (Ed.), Handbook of multivariate experimental psychology (pp. 355-402). Chicago: Rand McNally.

Cervone, D. \& Shoda, Y. (Eds.) (1999). The coherence of personality: Socialcognitive bases of consistency, variability, and organization. New York: Guilford Press.

Chen, L. S., Aggen, S. H., Nesselroade, J. R., \& Baltes, P. B. (2001). Short-term fluctuations in elderly people's sensiomotor functioning predict text and spatial memory performance: The MacArthur successful aging studies. Journal of Gerontology, 47, 100-116.

Collins, L. M., Hyatt, S. L., \& Graham, J. W. (2000). Latent transition analysis as a way of testing models of stage-sequential change in longitudinal data. In T. D. Little, K. U. Schnabel, \& J. Baumert (Eds.), Modeling longitudinal and multilevel data (pp. 147-162). Mahwah, NJ: Erlbaum.

Colvin, C. R. (1993). Childhood antecedents of young-adult judgability. Journal of Personality, 61, 611-635.

Cudeck, R. (1996). Mixed-effects models in the study of individual differences with repeated measures data. Multivariate Behavioral Research, 31, 371-403.

Cudeck, R., \& Klebe, K. J. (2002). Multiphase mixed-effects models for repeated measures data. Psychological Methods, 7, 41-63.

Curran, P. J., \& Bollen, K. A. (2001). The best of both worlds: Combining autoregressive and latent curve models. In L. M. Collins \& A. G. Sayer (Eds.), New methods for the analysis of change (pp. 105-136). Washington, DC: American Psychological Association.

Diener, E., Larsen, R. J., \& Emmons, R. A. (1984). Person $\times$ situation interactions: Choice of situations and congruence response models. Journal of Personality and Social Psychology, 47, 580-592.

Dodge, R. (1924). Problems of human variability. Science, 59, 263-270.

Duncan, T. E., Duncan, S. C., Strycker, L. A., Li, F., \& Alpert, A. (1999). An introduction to latent variable growth curve modeling. Mahwah, $\mathrm{NJ}$ : Lawrence Erlbaum Associates.

Eizenman, D. R., Nesselroade, J. R., Featherman, D. L., \& Rowe, J. W. (1997). Intraindividual variability in perceived control in an older sample: 
The MacArthur successful aging studies. Psychology of Aging, 12, 489-502.

Elder, G. H., Jr. (1998). Children of the Great Depression: Social change in life experience (25th anniversary edn.). Boulder, CO: Westview Press.

Epstein, S. (1980). The stability of behavior: II. Implications for psychological research. American Psychologist, 35, 790-806.

Embretson, S. E., \& Reise, S. P. (2000). Item response theory for psychologists. Mahwah, NJ: Lawrence Erlbaum Associates.

Fiske, D. W. (1972). Measuring the concepts of personality. Chicago, IL: Aldine Publishing.

Fiske, D. W., \& Rice, L. (1955). Intraindividual response variability. Psychological Bulletin, 52, 217-250.

Friedman, H. S., Tucker, J. S., Schwartz, J. E., Martin, L. R., Tomlinson-Keasey, C., Wingard, D. L., \& Criqui, M. H. (1995). Childhood conscientiousness and longevity: Health behaviors and the cause of death. Journal of Personality and Social Psychology, 68, 696-703.

Funder, D. C. (2001). The Personality Puzzle (2nd ed.). New York: Norton.

Funder, D. C., \& West, S. G. (Eds.) (1993). Viewpoints on personality: Consensus, self-other agreement, and accuracy in personality judgment [Special issue]. Journal of Personality, 64 (4).

Goldberg, L. R. (1992). The development of markers for the big-five factor structure. Psychological Assessment, 4, 26-42.

Haan, N., Millsap, R., \& Hartka, E. (1986). As time goes by: Change and stability in personality over fifty years. Psychology and Aging, 1, 220-232.

Heatherton, T. F. \& Weinberger, J. L. (Eds.) (1994). Can personality change? Washington DC: American Psychological Association.

Helson, R., \& Wink, P. (1992). Personality change in women from the early 40s to the early 50s. Psychology and Aging, 7 (1), 46-55.

Herrington, L. P. (1942). The relation of physiological and social indices of activity level. In Q. McNemar \& M. A. Merrill (Eds.), Studies in personality (pp. 125-146). New York: McGraw-Hill.

Jones, C. J., \& Meredith, W. (1996). Patterns of personality change across the life span. Psychology and Aging, 11, 57-65.

Kelley, H. H. (1973). The processes of causal attribution. American Psychologist, 28, 107-128.

Kendall, M. G., \& Stuart, A. (1977). The advanced theory of statistics (Vol. 1), New York: Macmillan.

Kenny, D. A., Kashy, D., \& Bolger, N. (1998). Data analysis in social psychology. In D. Gilbert, S. Fiske, \& G. Lindzey (Eds.), Handbook of social psychology (4th ed., pp. 233-265). New York: McGrawHill.

Kernis, M. H., Grannemann, B. D., \& Barclay, L. C. (1989). Stability and level of self-esteem as predictors of anger arousal and hostility. Journal of Personality and Social Psychology, 56, 1013-1023.

Kernis, M. H., Grannemann, B. D., \& Barclay, L. C. (1992). Stability of selfesteem: Assessment, correlates, and excuse making. Journal of Personality, 60, 621-644. 
Khoo, S.-T., \& West, S. G. (2002, in press). Longitudinal methods. In M. Eid \& E. Diener (Eds.), Handbook of psychological measurement: A multimethod perspective. Washington, DC: American Psychological Association.

Kluckhohn, C., \& Murray, H. A. (1953). Personality formation: The determinants. In C. Kluckhohn, H. A. Murray, \& D. Schneider (Eds.), Personality in nature, society, and culture (pp. 53-67). New York: Knopf.

Lamiell, J. T. (1997). Individuals and the differences between them. In R. Hogan, J. Johnson, \& S. Briggs (Eds.), Handbook of Personality Psychology (pp. 117-141). San Diego, CA: Academic.

Lang, F. R., Featherman, D. L., \& Nesselroade, J. R. (1997). Social self-efficacy and short-term variability in social relationships: The MacArthur successful aging studies. Psychology and Aging, 12, 657-666.

Larsen, R. J. (1990). Spectral analysis of psychological data. In A. Von Eye (Ed.), Statistical methods in longitudinal research, Volume II: Time series and categorical longitudinal data (pp. 319-349). Boston: Academic Press.

Lewin, K. (1935). A dynamic theory of personality. New York: McGraw-Hill.

Lindley, D. V., \& Smith, A. F. M. (1972). Bayes estimates for the linear model. Journal of the Royal Statistical Society. Series B (Methodological), 34, $1-41$.

Little, R. J. A., \& Schenker, N. (1995). Missing Data. In G. Arminger, C. C. Clogg, \& M. E. Sobel (Eds.), Handbook of Statistical Modeling for the Social and Behavioral Sciences (pp. 39-75). New York: Plenum.

Magnusson, D. (1998). The logic and implications of a person-oriented approach. In R. B. Cairns, L. R. Bergman, \& J. Kagan (Eds.), Methods and models for studying the individual: Essays in honor of Marian Radke-Yarrow (pp. 33-62). Thousand Oaks, CA: Sage.

Magnusson, D. (2000). The individual as the organizing principle in psychological inquiry: A holistic approach. In L. R. Bergman, R. B. Cairns, L.-G. Nilsson, \& L. Nyystedt (Eds.), Developmental science and the holistic approach (pp. 49-62). Mahwah, NJ: Lawrence Erlbaum Associates.

Magnusson, D., \& Torestäd, B. (1993). A holistic view of personality: A model revisited. Annual Review of Psychology, 44, 427-452.

McArdle, J. J., Ferrer-Caja, E., Hamagami, F., \& Woodcock, R. W. (2002). Comparative longitudinal structural analyses of the growth and decline of multiple intellectual abilities over the life span. Developmental Psychology, 38, $115-142$.

McCrae, R. R., \& Costa, P. T., Jr. (1990). Personality in adulthood. New York: Guilford.

McCrae, R. R., Costa, P. T., Jr., de Lima, M. P., Simões, A., Ostendorf, F., Angleitner, A., Marusic, I., Bratko, D., Caprara, G. V., Barbaranelli, C., Chae, J.-H., \& Peidmont, R. L. (1999). Age differences in personality across the adult life span: Parallels in five cultures. Developmental Psychology, 35, 466-477.

McDonald, R. P. (1981). Constrained least squares estimators of oblique common factors. Psychometrika, 46, 337-341.

Mehta, P., \& West, S. G. (2000). Putting the individual back in individual growth curves. Psychological Methods, 5, 23-43. 
Meredith, W., \& Tisak, J. (1990). Latent curve analysis. Psychometrika, 55, $107-122$.

Moskowitz, D. S. (1986). Comparison of self-reports, reports by knowledgeable informants, and behavioral observation data. Journal of Personality, 54, 294-317.

Moskowitz, D. S., \& Schwartz, J. C. (1982). Validity comparison of behavior counts and ratings by knowledgeable informants. Journal of Personality and Social Psychology, 42, 518-528.

Murray, H. A. (1938). Explorations in personality. New York: Oxford University Press.

Nasby, W., \& Read, N. W. (1997). The life voyage of a solo circumnavigator: Integrating theoretical and methodological perspectives. Journal of Personality, 65, 785-1068.

Nesselroade, J. R. (2000, August). Longitudinal design and modeling in the short run. Paper presented at the annual meeting of the American Psychological Association, Washington, DC.

Nesselroade, J. R., \& McArdle, J. J. (1997). On the mismatching of levels of abstraction in mathematical-statistical model fitting. In M. D. Franzen \& H. W. Reese (Eds.), Life-span developmental psychology: Biological and neuropsychological mechanisms (pp. 23-49). Hillsdale, NJ: Lawrence Erlbaum Associates.

Ozer, D. J. (1986). Consistency in personality: A methodological framework. Berlin: Springer-Verlag.

Ozer, D. J., \& Gjerde, P. F. (1989). Patterns of personality consistency and change from childhood through adolescence. Journal of Personality, 57, 483-508.

Pellegrino, J. W., \& Kail, R. V. (1982). Process analysis of spatial aptitude. In R. J. Sternberg (Ed.), Advances in the study of human intelligence (Vol. 1). Hillsdale, NJ: Erlbaum.

Raudenbush, S. W., \& Bryk, A. S. (2002). Hierarchical Linear Models: Applications and Data Analysis Methods (2nd ed.). Thousand Oaks, CA: Sage Publications.

Reis, H. T., \& Gable, S. L. (2000). Event sampling and other methods for studying daily experience. In H. T. Reis \& C. M. Judd (Eds.), Handbook of Research Methods in Social and Personality Psychology (pp. 190-222). New York: Cambridge University Press.

Roberts, B. W., \& DelVecchio, W. F. (2000). The rank-order consistency of personality from childhood to old age: A quantitative review of longitudinal studies. Psychological Bulletin, 126, 3-25.

Rogosa, D. R., \& Willett, J. B. (1985). Understanding correlates of change by modeling individual differences in growth. Psychometrika, 50, 203-228.

Runyan, W. (1983). Idiographic goals and the study of lives. Journal of Personality, 51, 413-437.

Schafer, J. L., \& Graham, J. W. (2002). Missing data: Our view of the state of the art. Psychological Methods, 7, 147-177.

Shoda, Y., Mischel, W., \& Wright, J. C. (1994). Intraindividual stability in the organization and patterning of behavior: Incorporating psychological 
situations into the idiographic analysis of personality. Journal of Personality and Social Psychology, 67, 674-687.

Singer, J. D., \& Willett, J. B. (2003). Applied Longitudinal Data Analysis: Modeling Change and Event Occurrence. New York: Oxford University Press.

Snyder, M. (1983). The influence of individuals on situations: Implications for understanding the links between personality and social behavior. Journal of Personality, 51, 497-516.

Stevens, S. S. (1951). Mathematics, measurement, and psychophysics. In S. S. Stevens (Ed.), Handbook of experimental psychology (pp. 1-49). New York: Wiley.

Stevenson, W. (1952). Some observations of the Q technique. Psychological Bulletin, 49, 483-498.

Thorndike, E. L. (1931). Human learning. New York: Appleton-Century-Crofts.

Tisak, J., \& Tisak, M. S. (2000). Permanency and ephemerality of psychological measures with application to organizational commitment. Psychological Methods, 5, 175-198.

Tucker, L. R. (1971). Relations of factor score estimates to their use. Psychometrika, 36, 427-436.

Tukey, J. W. (1986). Data analysis and behavioral science or learning to bear the quantitative man's burden by shunning badmandments. In L. V. Jones (Ed.), The collected works of John W. Tukey: Vol. III, Philosophy and principles of data analysis: 1949-1964 (pp. 187-390). Monterey, CA: Wadsworth \& Brooks (original unpublished work 1961).

von Eye, A. \& Clogg, C. C. (Eds.) (1996). Categorical variables in developmental research. Boston: Academic Press.

von Eye, A., Kreppner, K., Spiel, C., \& We-Sels, H. (1995). Life events' spacing and order in individual development. In T. A. Kindermann \& J. Valsiner (Eds.), Development of person-context relations (pp. 147-164). Hillsdale, NJ: Lawrence Erlbaum Associates.

West, S. G. (Ed.) (1983). Personality and prediction: Nomothetic and idiographic approaches [Special Issue]. Journal of Personality, 51 (3).

West, S. G. (in press). Towards finding the person in the data of personality. Journal of Personality.

West, S. G., \& Graziano, W. G. (Eds.) (1989). Long-term stability and change in personality [Special Issue]. Journal of Personality, 57 (2).

West, S. G., \& Hepworth, J. T. (1991). Statistical issues in the study of temporal data: Daily experiences. Journal of Personality, 59, 609-662.

Wiggins, J. S. (1991). Agency and communion as conceptual coordinates for understanding and measurement of interpersonal behavior. In W. Grove \& D. Cicchetti (Eds.), Thinking clearly about psychology: Essays in honor of Paul E. Meehl (Vol. 2, pp. 89-113). Minneapolis: University of Minnesota Press.

Willett, J. B., \& Sayer, A. G. (1994). Using covariance structure analysis to detect correlates and predictors of individual change over time. Psychological Bulletin, 116, 363-381. 
Willett, J. B., Singer, J. D., \& Martin, N. C. (1998). The design and analysis of longitudinal studies of development and psychopathology in context: Statistical models and methodological recommendations. Development and Psychopathology, 10, 395-426.

Winter, D. G., \& Barenbaum, N. B. (1999). History of modern personality theory and research. In L. A. Pervin \& O. P. John (Eds.), Handbook of personality: Theory and research (2nd ed., pp. 3-30). New York: Guilford Press. 
942 